\title{
A novel method for transpulmonary pressure estimation using fluctuation of central venous pressure
}

\author{
Miyako Kyogoku ${ }^{1}$ - Muneyuki Takeuchi ${ }^{1} \cdot$ Yu Inata $^{1} \cdot$ Nao Okuda $^{2} \cdot$ Yoshiyuki Shimizu $^{1} \cdot$ Takeshi Hatachi $^{1}$. \\ Kazue Moon ${ }^{1} \cdot$ Kazuya Tachibana ${ }^{3}$
}

Received: 10 April 2019 / Accepted: 19 July 2019 / Published online: 25 July 2019

(c) Springer Nature B.V. 2019

\begin{abstract}
The objective of the study is to develop a correction method for estimating the change in pleural pressure $(\Delta \mathrm{Ppl})$ and plateau transpulmonary pressure $\left(\mathrm{P}_{\mathrm{L}}\right)$ by using the change in central venous pressure $(\Delta \mathrm{CVP})$. Seven children (aged $<15$ years) with acute respiratory failure $\left(\mathrm{PaO}_{2} / \mathrm{F}_{\mathrm{I}} \mathrm{O}_{2}<300 \mathrm{mmHg}\right)$, who were paralyzed and mechanically ventilated with a PEEP of $<10 \mathrm{cmH}_{2} \mathrm{O}$ and had central venous catheters and esophageal balloon catheters placed for clinical purposes, were enrolled prospectively. We compared change in esophageal pressure ( $\triangle \mathrm{Pes}), \Delta \mathrm{CVP}$, and $\Delta \mathrm{Ppl}$ calculated using a corrected $\Delta \mathrm{CVP}$ (c $\Delta \mathrm{CVP}$-derived $\Delta \mathrm{Ppl}$ ). $\mathrm{c} \Delta \mathrm{CVP}$-derived $\Delta \mathrm{Ppl}$ was calculated as $\kappa \times \Delta \mathrm{CVP}$, where $\kappa$ was the ratio of the change in airway pressure ( $\Delta$ Paw) to $\Delta$ CVP during the occlusion test. $\Delta \Delta$ CVP-derived $\Delta \mathrm{Ppl}$ correlated better than $\Delta \mathrm{CVP}$ with $\Delta$ Pes $\left(\mathrm{R}^{2}=0.48\right.$, $\mathrm{p}=0.08$ vs. $\left.\mathrm{R}^{2}=0.14, \mathrm{p}=0.4\right)$ with lesser bias and precision in Bland-Altman analysis. The plateau $\mathrm{P}_{\mathrm{L}}$ calculated using the $\mathrm{c} \Delta$ CVP-derived $\Delta \mathrm{Ppl}\left(17.6 \pm 2.6 \mathrm{cmH}_{2} \mathrm{O}\right)$ correlated well with the $\Delta$ Pes-derived plateau $\mathrm{P}_{\mathrm{L}}\left(18.1 \pm 2.3 \mathrm{cmH}_{2} \mathrm{O}\right)\left(\mathrm{R}^{2}=0.90\right.$, $\mathrm{p}=0.001)$. Our correction method can estimate $\Delta \mathrm{Ppl}$ and plateau $\mathrm{P}_{\mathrm{L}}$ from $\Delta \mathrm{CVP}$ with a reasonable accuracy in paralyzed and mechanically ventilated pediatric patients with respiratory failure.
\end{abstract}

Keywords Central venous pressure $\cdot$ Esophageal pressure $\cdot$ Mechanical ventilation $\cdot$ Pleural pressure $\cdot$ Respiratory failure $\cdot$ Transpulmonary pressure

\section{Introduction}

Optimizing the transpulmonary pressure $\left(\mathrm{P}_{\mathrm{L}}\right)$ has been proposed as an integral component of the lung protective strategy in the management of acute respiratory distress

A part of the research data was presented by Miyako Kyogoku at 46th Symposium on the Society of Critical Care Medicine on January 23, 2017, in Honolulu, Hawaii, USA. syndrome (ARDS) [1]. Determination of $\mathrm{P}_{\mathrm{L}}$ requires the measurement of the esophageal pressure (Pes), which is a surrogate of pleural pressure (Ppl), by using an esophageal balloon catheter [2]. However, the measurement of Pes is complicated by technical issues, including issues related to correct positioning of the esophageal catheter, acquisition of accurate measurements, and interpretation of absolute Pes values [3]. This explains, at least in part, why the

\author{
Kazue Moon \\ moon@wch.opho.jp \\ Kazuya Tachibana \\ tatty@wch.opho.jp \\ 1 Department of Intensive Care Medicine, Osaka Women's \\ and Children's Hospital, 840 Murodo-cho, Izumi, \\ Osaka 594-1101, Japan \\ 2 Center for Infectious Diseases, Nara Medical University \\ Hospital, Nara, Japan \\ 3 Department of Anesthesiology, Osaka Women's \\ and Children's Hospital, Osaka, Japan
}


measurement of Pes is not widely used in clinical settings $[4,5]$.

The uncertainty associated with using the absolute Pes value as a surrogate of $\mathrm{Ppl}$ can be partly overcome by using a method recently developed by Grasso et al. [1] in which the change in Pes $(\Delta$ Pes), instead of the absolute value, is used to derive the plateau $\mathrm{P}_{\mathrm{L}}$. In this so-called elastance method, plateau $\mathrm{P}_{\mathrm{L}}$ can be calculated as follows:

Plateau $\mathrm{P}_{\mathrm{L}}=$ Pplat $\times(\Delta \mathrm{P}-\Delta \mathrm{Ppl}) / \Delta \mathrm{P}$

where Pplat is plateau pressure and $\Delta \mathrm{P}$ is driving pressure (plateau pressure - peak end-expiratory pressure). Since $\Delta \mathrm{Ppl}$ can be substituted by $\Delta$ Pes, Eq. (1) can also be expressed as follows:

Plateau $\mathrm{P}_{\mathrm{L}}=$ Pplat $\times(\Delta \mathrm{P}-\Delta \mathrm{Pes}) / \Delta \mathrm{P}$

This method does not require an absolute value of Pes, which can be influenced by several factors, including the balloon size, filling volume of the balloon, and elastance of the esophageal wall [6-8]; nonetheless, it still requires an esophageal balloon to obtain $\Delta$ Pes values.

The idea of estimating of $\mathrm{P}_{\mathrm{L}}$ without using an esophageal balloon catheter is attractive. The validity of using the change in central venous pressure $(\triangle \mathrm{CVP})$ as a surrogate of $\Delta \mathrm{Ppl}$ has been examined for decades $[9,10]$. However, several studies have reported that $\triangle$ CVP does not always accurately reflect $\Delta \mathrm{Ppl}$ [11], especially when the CVP is high [12]. Accordingly, $\Delta$ CVP has not been accepted as a surrogate of $\Delta \mathrm{Ppl}$. Furthermore, whereas the estimation of $\Delta \mathrm{Ppl}$ by using $\Delta \mathrm{CVP}$ has been attempted [9], there has not been a report of using $\Delta \mathrm{CVP}$ to estimate the plateau $\mathrm{P}_{\mathrm{L}}$ : another important variable used in the lung protective strategy [13].

The primary objective of this study was to develop and test the validity of a method of estimating $\Delta \mathrm{Ppl}$ by using $\Delta \mathrm{CVP}$; this method, would obviate the need of the esophageal balloon catheter. The secondary objective was to estimate the plateau $\mathrm{P}_{\mathrm{L}}$ using our correction method and demonstrate that the obtained plateau $\mathrm{P}_{\mathrm{L}}$ approximates well the plateau $\mathrm{P}_{\mathrm{L}}$ derived from $\Delta$ Pes $\left(\Delta\right.$ Pes-derived plateau $\left.\mathrm{P}_{\mathrm{L}}\right)$. A part of this work was previously presented at the 47th Critical Care Congress of the Society of Critical Care Medicine [14].

\section{Methods}

\subsection{Study design and patient selection}

This prospective study was conducted in the PICU of a tertiary children's hospital. The study was approved by the institutional review board (Approval Number: 904). Patients who were younger than 15 years with acute respiratory failure $\left(\mathrm{PaO}_{2} / \mathrm{F}_{\mathrm{I}} \mathrm{O}_{2}<300 \mathrm{mmHg}\right)$, were hemodynamically stable without ongoing fluid resuscitation and mechanically ventilated under neuromuscular blockade with a positive end-expiratory pressure (PEEP) of $<10 \mathrm{cmH}_{2} \mathrm{O}$, and had central venous catheters (CVCs) and esophageal balloon catheters placed for clinical purposes, were enrolled for 4 months ending July 2016. We excluded patients in whom the correct positioning of the esophageal balloon catheter could not be confirmed.

\subsection{Setting for measurement and recording}

A CVC (SMAC TM Plus double 17G, Medtronic, Dublin, Ireland) was placed via the internal jugular vein, with the tip located in the superior vena cava (SVC). Airway pressure (Paw) was measured at the junction of the respirator circuit and endotracheal tube. An esophageal balloon catheter (AVEA ${ }^{\mathrm{TM}}$ Ventilator Esophageal Pressure Monitoring Tube, IMI, Saitama, Japan) was nasally inserted into the mid-lower third of the esophagus. Pes was measured in the supine position. Correct positioning of the esophageal balloon catheter was confirmed using the positive pressure occlusion test (OT) $[3,15]$. The test was performed by measuring the changes in Pes and Paw ( $\Delta$ Pes and $\Delta$ Paw, respectively) while the chest wall of a paralyzed patient was compressed. Specifically, the airway opening was occluded at the end-expiration and the rib cage was gently squeezed to an extent that Paw on the bedside monitor increased by approximately $10 \mathrm{cmH}_{2} \mathrm{O}$. This process was repeated three times and the values were averaged for analysis (Fig. 1A). The catheter position was deemed correct when the ratio of $\Delta$ Pes to $\Delta$ Paw was between 0.8 and $1.2[3]$.

CVP, Pes, and Paw were simultaneously displayed on a bedside monitor (BSM-6701, Nihon Kohden, Tokyo, Japan), which used pressure transducers of the same model (pediatric TruWave pressure monitoring transducer, Edwards, California, United States), and the data were automatically transferred to and recorded in an electric medical chart system (GAIA, Nihon Kohden, Tokyo, Japan) every 0.004 s using digital signals. Because the Paw, Pes, and CVP waveforms have cardiogenic oscillations, pressure values at the peak of the cardiogenic oscillations were used in the calculations (Fig. 1B).

\subsection{Measurement and comparison of three variables that reflect $\Delta \mathrm{Ppl}$}

First, we measured three variables that reflect $\Delta \mathrm{Ppl}: \Delta \mathrm{Pes}$, $\Delta \mathrm{CVP}$, and $\Delta \mathrm{Ppl}$ calculated using the corrected $\Delta \mathrm{CVP}$ (c $\Delta$ CVP-derived $\Delta \mathrm{Ppl}$ ). To calculate $\Delta \mathrm{Ppl}$ by using the correction method, OT was performed to obtain a ratio of $\Delta \mathrm{Paw}$ to $\triangle$ CVP (Fig. 1B). This ratio is expressed as " $\kappa$ " and it is 


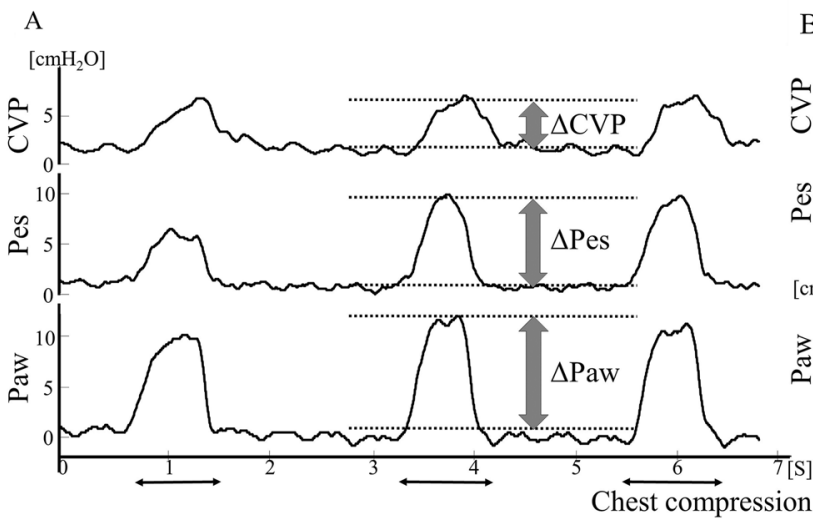

B
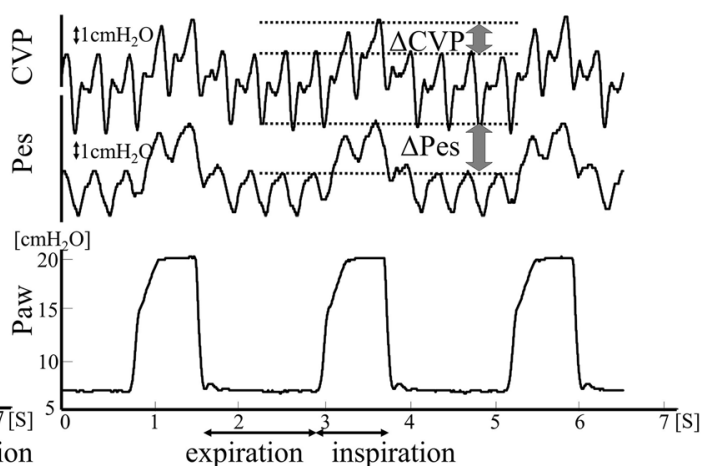

Fig. 1 Pressure waveforms of CVP, Pes, and Paw during the positive pressure occlusion test (A) and during the mechanical ventilation (B). A During chest compressions in the occlusion test, Pes and Paw waveforms fluctuate in a similar manner. The ratio of $\Delta \mathrm{Paw}$ to $\Delta \mathrm{CVP}$ was obtained and expressed as " $\kappa$." Note that $\Delta$ Paw should be equal to $\Delta \mathrm{Ppl}$ during occlusion test provided the esophageal balloon catheter position is correct. B During mechanical ventilation, $\Delta \mathrm{Ppl}$ can be

calculated by multiplying $\kappa$ with $\Delta \mathrm{CVP}$, assuming the ratio of $\Delta \mathrm{Ppl}$ to $\Delta \mathrm{CVP}$ during the occlusion test and during mechanical ventilation was the same. Pressure values at the peak of the cardiogenic oscillations were used for calculation. CVP central venous pressure, Pes esophageal pressure, $P a w$ airway pressure, $\triangle P e s$ change in esophageal pressure, $\triangle P a w$ change in airway pressure, $\triangle C V P$ change in central venous pressure, $\Delta P p l$ change in pleural pressure

presumably the same as the ratio of $\Delta \mathrm{Ppl}$ to $\Delta \mathrm{CVP}$ because $\Delta \mathrm{Paw}$ should be equal to $\Delta \mathrm{Ppl}$ during airway occlusion. Next, the patient was placed back to the original ventilator settings. After 5 min of stabilization, $\Delta$ Pes and $\triangle C V P$ were measured during mechanical ventilation. Assuming the ratio of $\Delta \mathrm{Ppl}$ to $\Delta \mathrm{CVP}$ during the occlusion test and during mechanical ventilation is the same, $\mathrm{c} \Delta \mathrm{CVP}$-derived $\Delta \mathrm{Ppl}$ can be expressed as follows:

\section{$\mathrm{c} \Delta$ CVP-derived $\Delta \mathrm{Ppl}$}

$=\kappa \times \Delta \mathrm{CVP}$ during the mechanical ventilation

where $\kappa$ is a ratio of $\Delta$ Paw to $\Delta C V P$ during OT.

Next, the three variables were compared. Since $\Delta \mathrm{Pes}$ is widely accepted as a gold standard surrogate for $\Delta \mathrm{Ppl}$ [3], we assumed $\Delta \mathrm{Pes}$ was equal to $\Delta \mathrm{Ppl}$. Then, we examined whether $\Delta \mathrm{CVP}$ and $\mathrm{c} \Delta \mathrm{CVP}$-derived $\Delta \mathrm{Ppl}$ could reasonably estimate $\Delta$ Pes.

\subsection{Calculation and comparison of plateau $P_{L}$ by using $\Delta$ Pes and $C \Delta C V P$-derived $\Delta P p l$}

Each of the variables obtained in the above-described process was used to calculate the plateau $\mathrm{P}_{\mathrm{L}}(\Delta$ Pes-derived plateau $\mathrm{P}_{\mathrm{L}}$ and $\mathrm{c} \Delta \mathrm{CVP}$-derived plateau $\mathrm{P}_{\mathrm{L}}$ ). $\Delta$ Pes-derived plateau $P_{L}$ was calculated using Eq. (2). Based on Eqs. (1) and (3), $c \Delta$ CVP-derived plateau $P_{L}$ was calculated as follows:

c $\Delta$ CVP-derived plateau $\mathrm{P}_{L}$

$=$ Pplat $\times(\Delta \mathrm{P}-\mathrm{c} \Delta \mathrm{CVP}$-derived $\Delta \mathrm{Ppl}) / \Delta \mathrm{P}$

$=$ Pplat $\times(\Delta \mathrm{P}-\kappa \times \Delta \mathrm{CVP}$ during mechanical ventilation $) / \Delta \mathrm{P}$

Finally, $\mathrm{c} \Delta \mathrm{CVP}$-derived plateau $\mathrm{P}_{\mathrm{L}}$ was compared to $\Delta$ Pes-derived plateau $P_{L}$, which was used as a gold standard surrogate for plateau $P_{L}$, to examine how closely and reliably they approximate each other.

\subsection{Statistics}

Continuous variables are presented as means \pm standard deviations and were compared using the Student's $t$ test. The Bland-Altman analysis was used to analyze agreements between $\Delta C V P$ and $\Delta$ Pes, between $\mathrm{c} \Delta \mathrm{CVP}$-derived $\Delta \mathrm{Ppl}$ and $\Delta \mathrm{Pes}$, and between $\mathrm{c} \Delta \mathrm{CVP}$-derived plateau $\mathrm{P}_{\mathrm{L}}$ and $\Delta$ Pes-derived plateau $\mathrm{P}_{\mathrm{L}}$. The correlation of $\Delta \mathrm{CVP}$ and $\mathrm{c} \Delta \mathrm{CVP}$-derived $\Delta \mathrm{Ppl}$ with $\Delta \mathrm{Pes}$ was tested, and the correlation of $c \Delta C V P$-derived plateau $\mathrm{P}_{\mathrm{L}}$ with $\Delta$ Pes-derived plateau $\mathrm{P}_{\mathrm{L}}$ was also tested. A $\mathrm{p}$ value of less than 0.05 was considered statistically significant for all analyses. Analyses were performed using EZR Ver. 1.36 (Saitama Medical Center, Jichi Medical University, Saitama, Japan), which is a graphical user interface for R (The R Foundation for Statistical Computing, Vienna, Austria).

\section{Results}

Twelve patients were enrolled in this study; five of them were excluded because correct positioning of the esophageal balloon could not be confirmed during the OT. Therefore, seven patients were included in the final analysis. The patient characteristics are shown in Table 1. 
Table 1 Patient characteristics

\begin{tabular}{llllllll}
\hline Case & Age (months) & Weight $(\mathrm{kg})$ & Diagnosis & Pplat/PEEP $\left(\mathrm{cmH}_{2} \mathrm{O}\right)$ & $\mathrm{PaO}_{2} / \mathrm{F}_{\mathrm{I}} \mathrm{O}_{2}(\mathrm{mmHg})$ & $\mathrm{CVP}(\mathrm{mmHg})$ & $\mathrm{TV}(\mathrm{ml} / \mathrm{kg})$ \\
\hline 1 & 1 & 2.6 & S/P cardiac surgery & $20 / 6$ & 195 & 8 & 7.0 \\
2 & 4 & 3.9 & S/P cardiac surgery & $19 / 5$ & 168 & 5 & 9.6 \\
3 & 31 & 10.8 & Pneumonia & $23 / 9$ & 243 & 9 & 7.3 \\
4 & 1 & 3.2 & S/P cardiac surgery & $26 / 6$ & 96 & 188 & 13 \\
5 & 0 & 2.8 & S/P cardiac surgery & $21 / 6$ & 204 & 10 & 10.8 \\
6 & 0 & 3.1 & S/P cardiac surgery & $22 / 6$ & 260 & 9.7 \\
7 & 12 & 7.7 & Pneumonia & $21 / 7$ & $193 \pm 50$ & 5 & $8.1 \pm 2.7$ \\
Mean \pm SD & $7 \pm 11$ & $4.8 \pm 2.9$ & & $22 \pm 2 / 6.4 \pm 1.2$ & $9.4 \pm 1.2$ \\
\hline
\end{tabular}

${ }^{\text {a }}$ Postoperative respiratory failure after correction of congenital heart disease

\subsection{Measurement and comparison of three variables that reflect $\Delta \mathrm{Ppl}$}

Means and standard deviations of the three variables that reflect $\Delta \mathrm{Ppl}(\Delta \mathrm{Pes}, \Delta \mathrm{CVP}$, and $\mathrm{c} \Delta \mathrm{CVP}$-derived $\Delta \mathrm{Ppl})$ were $3.0 \pm 0.8 \mathrm{cmH}_{2} \mathrm{O}, 1.8 \pm 0.5 \mathrm{cmH}_{2} \mathrm{O}$, and $2.7 \pm 0.6 \mathrm{cmH}_{2} \mathrm{O}$ (Table 2). Correlations of $\Delta \mathrm{CVP}$ and $\mathrm{c} \Delta \mathrm{CVP}$-derived $\Delta \mathrm{Ppl}$ with $\Delta$ Pes are shown in Fig. 2A; $c \Delta$ CVP-derived $\Delta \mathrm{Ppl}$ correlated better with $\Delta$ Pes than $\Delta C V P \operatorname{did}\left(R^{2}=0.48, p=0.083\right.$ vs. $\left.\mathrm{R}^{2}=0.14, \mathrm{p}=0.407\right)$. The Bland-Altman analysis for the agreement between $\mathrm{c} \Delta \mathrm{CVP}$-derived $\Delta \mathrm{Ppl}$ and $\Delta$ Pes showed a bias of $0.3 \mathrm{cmH}_{2} \mathrm{O}$ and precision of $0.6 \mathrm{cmH}_{2} \mathrm{O}$, whereas the bias and precision were $1.2 \mathrm{cmH}_{2} \mathrm{O}$ and $0.8 \mathrm{cmH}_{2} \mathrm{O}$, respectively, for the agreement between $\triangle \mathrm{CVP}$ and $\Delta \mathrm{Pes}$. Both bias and precision were lesser when using $\mathrm{c} \Delta \mathrm{CVP}$-derived $\Delta \mathrm{Ppl}$ compared with when using $\Delta \mathrm{CVP}$ (Fig. 2B, C).

\subsection{Calculation and comparison of plateau $P_{L}$ by using the $\Delta \mathrm{Pes}$ and $\mathrm{c} \Delta \mathrm{CVP}$-derived $\Delta \mathrm{Ppl}$}

$\Delta$ Pes-derived plateau $\mathrm{P}_{\mathrm{L}}$ and $\mathrm{c} \Delta \mathrm{CVP}$-derived plateau $\mathrm{P}_{\mathrm{L}}$ were $17.6 \pm 2.6 \mathrm{cmH}_{2} \mathrm{O}$ and $18.1 \pm 2.3 \mathrm{cmH}_{2} \mathrm{O}$, respectively.
Correlations of c $\Delta$ CVP-derived plateau $\mathrm{P}_{\mathrm{L}}$ with $\Delta$ Pesderived plateau $\mathrm{P}_{\mathrm{L}}$ are shown in Fig. $3 \mathrm{~A}$. The $\mathrm{c} \Delta \mathrm{CVP}$ derived plateau $\mathrm{P}_{\mathrm{L}}$ correlated well with $\Delta$ Pes-derived plateau $P_{L}\left(R^{2}=0.90, p=0.001\right)$. The Bland-Altman analysis for the agreement between $c \Delta$ CVP-derived plateau $\mathrm{P}_{\mathrm{L}}$ and $\Delta$ Pes-derived plateau $\mathrm{P}_{\mathrm{L}}$ showed a bias of $-0.4 \mathrm{cmH}_{2} \mathrm{O}$ and precision of $0.8 \mathrm{cmH}_{2} \mathrm{O}$ (Fig. 3B).

\section{Discussion}

We have developed a novel correction method to estimate $\Delta \mathrm{Ppl}$ by using $\Delta \mathrm{CVP}$ in paralyzed and mechanically ventilated pediatric patients with acute respiratory failure. The correction method was able to estimate $\Delta$ Pes more accurately than the method using $\triangle \mathrm{CVP}$. Furthermore, the c $\triangle$ CVP-derived plateau $\mathrm{P}_{\mathrm{L}}$ (plateau $\mathrm{P}_{\mathrm{L}}$ derived from $\Delta C V P$ by using our correction method) had high correlation with $\Delta$ Pes-derived plateau $\mathrm{P}_{\mathrm{L}}$.

Monitoring and limiting the tidal change in $\mathrm{P}_{\mathrm{L}}\left(\Delta \mathrm{P}_{\mathrm{L}}\right)$ and plateau $\mathrm{P}_{\mathrm{L}}$ has been recommend to minimize the stress applied to the lungs in patients with ARDS [13]. However,

Table 2 Variables measured to obtain the change in pleural pressure and plateau transpulmonary pressure

\begin{tabular}{llllllll}
\hline Case & $\Delta$ Pes/ $/$ Paw during OT & $\begin{array}{l}\Delta \text { Paw/ } \Delta C V P \\
\text { during OT }(\kappa)\end{array}$ & $\Delta$ Pes $\left(\mathrm{cmH}_{2} \mathrm{O}\right)$ & $\Delta \mathrm{CVP}\left(\mathrm{cmH}_{2} \mathrm{O}\right)$ & $\begin{array}{l}\mathrm{c} \Delta \mathrm{CVP} \text {-derived } \\
\Delta \mathrm{Ppl}\left(\mathrm{cmH}_{2} \mathrm{O}\right)\end{array}$ & $\begin{array}{l}\Delta \text { Pes-derived } \\
\text { plateau } \mathrm{P}_{\mathrm{L}} \\
\left(\mathrm{cmH}_{2} \mathrm{O}\right)\end{array}$ & $\begin{array}{l}\mathrm{c} \Delta \mathrm{CVP} \text {-derived } \\
\text { plateau } \mathrm{P}_{\mathrm{L}} \\
\left(\mathrm{cmH}_{2} \mathrm{O}\right)\end{array}$ \\
\hline 1 & 0.84 & 1.23 & 2.9 & 2.5 & 3.1 & 15.8 & 15.5 \\
2 & 0.91 & 1.55 & 2.5 & 1.1 & 1.7 & 15.6 & 16.8 \\
3 & 0.80 & 1.35 & 3.0 & 1.9 & 2.6 & 18.1 & 18.7 \\
4 & 1.05 & 1.63 & 3.0 & 1.5 & 2.5 & 22.2 & 2.8 \\
5 & 0.95 & 1.92 & 2.8 & 1.5 & 2.8 & 17.0 & 17.0 \\
6 & 0.84 & 1.33 & 2.3 & 2.2 & 2.9 & 18.8 & 18.1 \\
7 & 0.89 & 1.62 & 4.8 & 2.3 & 3.7 & 13.8 & 15.5 \\
Mean \pm SD & $0.90 \pm 0.08$ & $1.52 \pm 0.22$ & $3.0 \pm 0.8$ & $1.8 \pm 0.5$ & $2.7 \pm 0.6$ & $17.3 \pm 2.5$ & $17.8 \pm 2.3$ \\
\hline
\end{tabular}

$\Delta P e s$ change in esophageal pressure, $\triangle P a w$ change in airway pressure, $O T$ occlusion test, $\triangle C V P$ change in central venous pressure, $\Delta P p l$ change in pleural pressure, $c \Delta C V P$-derived $\Delta P p l \Delta \mathrm{Ppl}$ calculated using a corrected $\Delta \mathrm{CVP}, \Delta$ Pes-derived plateau $P_{L}$ plateau $\mathrm{P}_{\mathrm{L}}$ derived from $\Delta \mathrm{Pes}$, $c \Delta$ CVP-derived plateau $P_{L}$ plateau $\mathrm{P}_{\mathrm{L}}$ derived from corrected $\Delta \mathrm{CVP}$ 


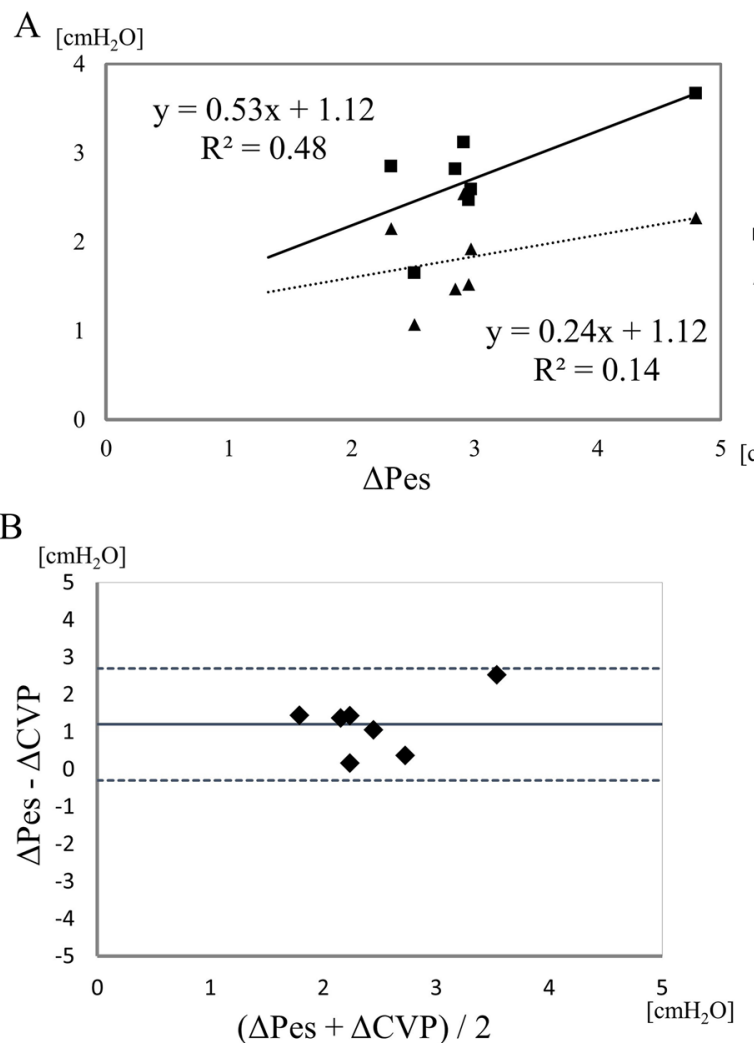

Fig. 2 Correlations of $\Delta C V P$ and $\mathrm{c} \Delta \mathrm{CVP}$-derived $\Delta \mathrm{Ppl}$ with $\Delta \mathrm{Pes}$ (A) and the Bland-Altman analysis for the agreement between $\Delta \mathrm{CVP}$ and $\Delta$ Pes $(\mathbf{B})$ and between $\mathrm{c} \Delta \mathrm{CVP}$-derived $\Delta \mathrm{Ppl}$ and $\Delta \mathrm{Pes}(\mathbf{C})$. A A solid line represents a simple linear regression line of $\Delta C V P$. A broken line represents a simple linear regression line of $\mathrm{c} \Delta \mathrm{CVP}$-derived

Pes monitoring is still seldom used in the implementation of such a strategy in clinical settings, partly due to the difficulty of properly positioning the esophageal balloon, of finding the best filling volume of the balloon, and of interpreting the obtained values [3]. The elastance method that uses the change in Pes during mechanical ventilation, instead of the absolute values, to calculate chest wall elastance can overcome the challenge of obtaining accurate absolute Pes values [1]. Furthermore, a calibration procedure to make the measurement of absolute values of Pes more reliable by finding the best filling volume may help in the implementation of Pes measurement in clinical settings [7]. However, these methods still require an esophageal balloon and some degree of expertise. Accordingly, esophageal balloons were used in only $0.8 \%$ of the patients with ARDS in a recent survey [16].

On the other hand, it is not uncommon for the mechanically ventilated patient with respiratory failure to have a CVC inserted via internal jugular vein. Changes in the $\mathrm{Ppl}$ that are associated with respiration are reflected in the changes in CVP obtained from SVC [12]. Studies have been conducted to investigate whether $\triangle \mathrm{CVP}$ can be used to estimate $\Delta \mathrm{Ppl}$ without using an esophageal balloon catheter.
- $\mathrm{c} \Delta \mathrm{CVP}$-derived $\Delta \mathrm{Ppl}$

$\triangle \triangle \mathrm{CVP}$

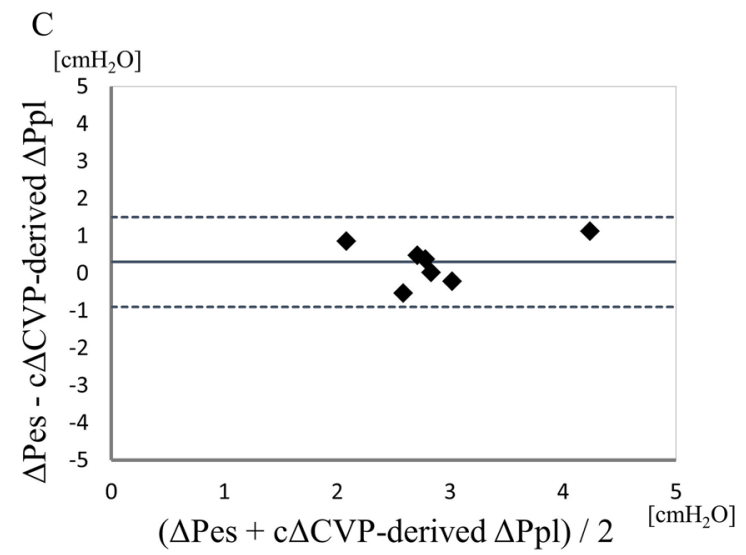

$\Delta$ Ppl. B, C Solid lines, bias (B $1.2 \mathrm{cmH}_{2} \mathrm{O}$, C $0.3 \mathrm{cmH}_{2} \mathrm{O}$ ); broken lines, $\pm 1.96 \mathrm{SD}$ of the bias $\left(\mathbf{B} 2.7,-0.3 \mathrm{cmH}_{2} \mathrm{O} ; \mathbf{C} 1.5,-0.8\right.$ $\left.\mathrm{cmH}_{2} \mathrm{O}\right) . \Delta C V P$ change in central venous pressure, $\Delta P p l$ change in pleural pressure, $c \Delta C V P$-derived $\Delta P p l \Delta \mathrm{Ppl}$ calculated using a corrected $\Delta \mathrm{CVP}, \Delta P e s$ change in esophageal pressure

Although several studies have shown there is some correlation of $\Delta C V P$ with $\Delta$ Pes $[9,10,17]$, conflicting data showing there is poor correlation have also been reported [11, 12]. Consequently, the use of $\Delta \mathrm{CVP}$ as a surrogate of $\Delta \mathrm{Ppl}$, while appealing, is not widely accepted. Thus, we developed a simple correction method that would make it possible to derive $\Delta \mathrm{Ppl}$ from $\Delta \mathrm{CVP}$ without an esophageal balloon catheter. Our study demonstrated that our correction method improved the accuracy of $\Delta \mathrm{Ppl}$ estimation by using $\Delta \mathrm{CVP}$ in paralyzed, mechanically ventilated pediatric patients. Furthermore, our correction method could be used to estimate the plateau $\mathrm{P}_{\mathrm{L}}$ with a clinically acceptable accuracy without using an esophageal balloon.

There were several limitations in our study. First, our study was conducted in a small population. In our experience, it is not uncommon for pediatric patients to fail OT even if the position of the balloon appears appropriate on $\mathrm{X}$-ray. We aimed to include 10 patients for the final analysis based on the population size $(n=9-10)$ of the previous studies $[9,10]$. We enrolled 12 patients with the assumption that about $15 \%$ of the patients would not pass the occlusion test. In the current study, however, 5 (42\%) of 12 cases were 
A

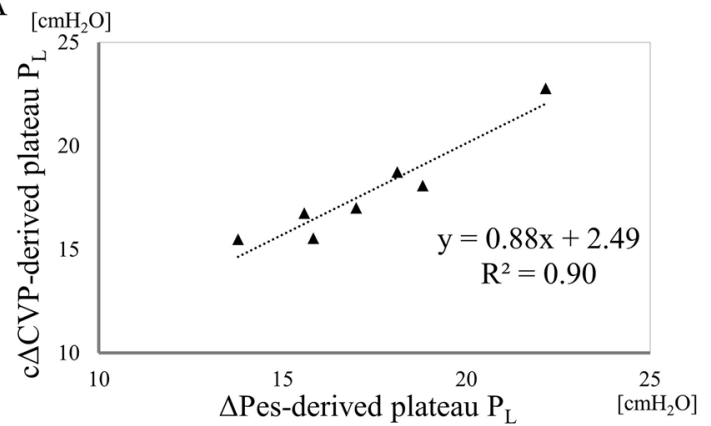

B

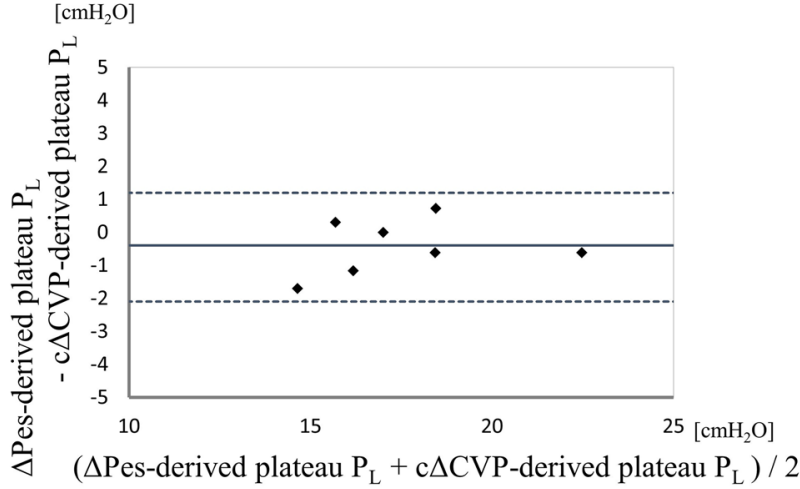

Fig. 3 Correlation between $c \Delta C V P$-derived plateau $\mathrm{P}_{\mathrm{L}}$ and $\Delta$ Pesderived plateau $\mathrm{P}_{\mathrm{L}}(\mathbf{A})$. The Bland-Altman analysis for the agreement between $\mathrm{c} \triangle \mathrm{CVP}$-derived plateau $\mathrm{P}_{\mathrm{L}}$ and $\Delta$ Pes-derived plateau $\mathrm{P}_{\mathrm{L}}(\mathbf{B})$. A A broken line represents a simple linear regression line. $\mathbf{B}$ A solid line, bias $\left(-0.4 \mathrm{cmH}_{2} \mathrm{O}\right)$; broken line, $\pm 1.96 \mathrm{SD}$ of the bias (1.2, $\left.-2.1 \mathrm{cmH}_{2} \mathrm{O}\right) . c \Delta C V P$-derived plateau $P_{L}$ plateau $\mathrm{P}_{\mathrm{L}}$ derived from the corrected value of change in CVP, $\Delta$ Pes-derived plateau $P_{L}$ plateau $\mathrm{P}_{\mathrm{L}}$ derived from the change in Pes

excluded because they did not pass OT despite the seemingly correct position of the balloon on the X-ray. This speaks to the necessity of a method to estimate transpulmonary pressure without an esophageal balloon. Second, the patients included in the study were all young. In adults, who have a higher ratio of chest wall elastance to lung elastance, the influence of $\Delta \mathrm{Ppl}$ estimation error on the value of estimated plateau $\mathrm{P}_{\mathrm{L}}$ would increase based on Eq. (1). Thus, the estimation of $c \Delta C V P$-derived plateau $\mathrm{P}_{\mathrm{L}}$ using our correction method may be more prone to errors in adults. Third, in this study, cases of severe ARDS with a high chest wall elastance who would benefit most from transpulmonary pressure measurement were not included. This is partly because we excluded patients requiring PEEP $\geq 10 \mathrm{cmH}_{2} \mathrm{O}$ for whom opening the respiratory circuit to perform OT would be clearly harmful. It remains to be tested whether our method can be applied to such cases with a high chest wall elastance or severe ARDS. Fourth, most of our patients underwent cardiac surgery prior to developing respiratory failure. While the sternum was closed in all patients, it is yet unknown as to how this may have affected their chest wall properties. Another limitation arises from the assumption that the ratio of $\Delta \mathrm{Paw}$ to $\Delta \mathrm{CVP}$ during $\mathrm{OT}$ is the same as the ratio of $\Delta \mathrm{Ppl}$ to $\Delta \mathrm{CVP}$ during mechanical ventilation. We have not confirmed whether this assumption is true in various clinical conditions, such as those associated with extremely high or low CVP levels. Whereas the deviation of $\triangle \mathrm{CVP}$ from $\triangle \mathrm{Ppl}$ has been reported at different levels of CVP $[9,12]$, we reasoned that it was unlikely that the absolute CVP values would affect our correction method, which uses the ratio of $\Delta$ Paw to $\triangle \mathrm{CVP}$. Furthermore, we performed OT immediately before measuring $\triangle \mathrm{CVP}$ during mechanical ventilation to minimize the possible effects due to the change in intravascular volume status. Nonetheless, further research is required to test whether intravascular volume status affects the accuracy of our method. Finally, it remains unclear whether our method can be applied to spontaneously breathing patients with mechanical ventilatory support because this study was conducted only in paralyzed patients. This could be a potential area of interest in future studies.

In conclusion, we have shown that our correction method can estimate $\Delta \mathrm{Ppl}$ from $\Delta \mathrm{CVP}$ with a reasonable accuracy in paralyzed and mechanically ventilated pediatric patients with acute respiratory failure. The method can help in the assessment of $\Delta \mathrm{P}_{\mathrm{L}}$ and plateau $\mathrm{P}_{\mathrm{L}}$ without using an esophageal balloon catheter. Validity of our correction method needs to be confirmed in various patient populations.

Author contributions MK designed the study, contributed to data collection, interpretation of data and wrote the initial draft of the manuscript. MT designed the study and contributed to analysis. YI contributed to analysis and interpretation of data, and assisted in the preparation of the manuscript. All other authors have contributed to data collection and critically reviewed the manuscript. All authors approved the final version of the manuscript, and agree to be accountable for all aspects of the work in ensuring that questions related to the accuracy or integrity of any part of the work are appropriately investigated and resolved.

Funding This project was partially funded by the Grant-in-aid for Community Health and Medical Care from Osaka University Medical School Alumni.

\section{Compliance with ethical standards}

Conflict of interest The authors disclose no conflict of interest.

\section{References}

1. Grasso S, Terragni P, Birocco A, Urbino R, Del Sorbo L, Filippini $\mathrm{C}$, et al. ECMO criteria for influenza A (H1N1)-associated ARDS: role of transpulmonary pressure. Intensive Care Med. 2012;38:395-403. 
2. Talmor D, Sarge T, Malhotra A, O’Donnell CR, Ritz R, Lisbon $A$, et al. Mechanical ventilation guided by esophageal pressure in acute lung injury. N Engl J Med. 2008;359:2095-104.

3. Akoumianaki E, Maggiore SM, Valenza F, Bellani G, Jubran A, Loring $\mathrm{SH}$, et al. The application of esophageal pressure measurement in patients with respiratory failure. Am J Respir Crit Care Med. 2014;189:520-31.

4. Hedenstierna G. Esophageal pressure: benefit and limitations. Minerva Anestesiol. 2012;78:959-66.

5. Brochard L. Measurement of esophageal pressure at bedside: pros and cons. Curr Opin Crit Care. 2014;20:39-46.

6. Mead J, Mcilroy MB, Selverstonez NJ, Kriete BC. Measurement of intraesophageal pressure. J Appl Physiol. 1955;7(5):491-5.

7. Mojoli F, Iotti GA, Torriglia F, Pozzi M, Volta CA, Bianzina S, et al. In vivo calibration of esophageal pressure in the mechanically ventilated patient makes measurements reliable. Crit Care. 2016;20:98. https://doi.org/10.1186/s13054-016-1278-5.

8. Hedenstierna G, Järnberg PO, Torsell L, Gottlieb I. Esophageal elastance in anesthetized humans. J Appl Physiol. 1983;54:1374-8.

9. Walling PT. a Comparison of Oesophageal. Br J Anaesth. 1976;48:475-9. https://doi.org/10.1093/bja/48.5.475.

10. Flemale A, Gillard C, Dierckx JP. Comparison of central venous, oesophageal and mouth occlusion pressure with water-filled catheters for estimating pleural pressure changes in healthy adults. Eur Respir J. 1988;1:51-7.
11. Bellemare P, Goldberg P, Magder SA. Variations in pulmonary artery occlusion pressure to estimate changes in pleural pressure. Intensive Care Med. 2007;33:2004-8.

12. Ostrander L, Schneider A, Burma G, Kreul J. A comparison of central venous pressure and pleural pressure in supine dogs. Respir Physiol. 1977;31:63-70.

13. Mauri T, Yoshida T, Bellani G, Goligher EC, Carteaux G, Rittayamai N, et al. Esophageal and transpulmonary pressure in the clinical setting: meaning, usefulness and perspectives. Intensive Care Med. 2016;42:1360-73.

14. Kyogoku M, Takeuchi M, Shimizu Y, Hatachi T, Moon K, Tachibana K. Comparison of Pes-derived and CVP-derived transpulmonary pressure in immobilized hypoxemic children. Crit Care Med. 2016;44:313.

15. Lanteri CJ, Kano S, Sly PD. Validation of esophageal pressure occlusion test after paralysis. Pediatr Pulmonol. 1994;17:56-62.

16. Bellani G, Laffey JG, Pham T, Fan E, Brochard L, Esteban A, et al. Epidemiology, patterns of care, and mortality for patients with acute respiratory distress syndrome in intensive care units in 50 countries. J Am Med Assoc (JAMA). 2016;315:788-800.

17. Hylkema BS, Barkmeijer-Degenhart P, van der Mark TW, Peset $\mathrm{R}$, Sluiter HJ. Central venous versus esophageal pressure changes for calculation of lung compliance during mechanical ventilation. Crit Care Med. 1983;11(4):271-5.

Publisher's Note Springer Nature remains neutral with regard to jurisdictional claims in published maps and institutional affiliations. 